\title{
Diodos emissores de luz e concentrações de BAP na multiplicação in vitro de morangueiro
}

\author{
Light-emitting diodes and BAP concentrations in the in vitro strawberry multiplication
}

\section{Paulo Sérgio Gomes da Rocha ${ }^{\mathrm{I}}{\text { Roberto Pedroso de } \text { Oliveira }^{\mathrm{I}^{*}} \text { Walkyria Bueno Scivittaro }}^{\mathrm{I}}$ Ulisses Lyra dos Santos ${ }^{\text {II }}$}

\section{RESUMO}

Realizou-se um estudo para avaliar o efeito de fontes de luz na micropropagação de morangueiro, com níveis crescentes de BAP no meio de cultivo. Para tanto, inocularamse gemas de brotações da cultivar 'Sabrosa' em meio MS com $30 \mathrm{~g} \mathrm{~L}^{-1}$ de sacarose, $100 \mathrm{mg} \mathrm{L}^{-1}$ de mio-inositol, $7 \mathrm{~g} \mathrm{~L}^{-1}$ de ágar e BAP $\left(0 ; 0,3\right.$; 0,6; 0,9; e 1,5mg $\left.L^{-1}\right)$, em pH 5,8. Os explantes foram cultivados a $25+2^{\circ} \mathrm{C}$, com 16 horas de fotoperíodo $e$ luminosidade de $20 \mu \mathrm{mol} \mathrm{m} \mathrm{m}^{-2} \mathrm{~s}^{-1}$, esta última fornecida por diferentes fontes de luz (LED azul-EDEB 3LA1, LED verdeEDET 3LA1, LED vermelho-EDER 3LA3, lâmpada fluorescente Growlux e lâmpada fluorescente branca). Os tratamentos foram dispostos em delineamento inteiramente ao acaso em um fatorial $5 \times 5$ (concentrações de BAP x fontes de luz), com seis repetições. $O$ experimento foi repetido em três subcultivos sucessivos de 35 dias cada. Nestes avaliaram-se o número de brotações por explante e a altura das brotações. Ao final do terceiro subcultivo, determinaram-se, ainda, as concentrações de carotenoides e de clorofilas a e $b$, independentemente do nível de BAP. Maior número de brotações por explante foi obtido sob LEDs vermelhos e verdes. Concentrações de BAP no meio de cultura entre 0,82 e $1,22 \mathrm{mg} \mathrm{L}^{-1}$, dependendo da fonte de luz, proporcionaram maior multiplicação in vitro de brotações. Sob todas as fontes de luz foram obtidas brotações de maior comprimento em meio isento de BAP. Brotações cultivadas sob LEDs vermelhos apresentaram maior quantidade de pigmentos fotossintéticos, enquanto aquelas sob LEDs verdes e lampadas Growlux apresentaram a menor.

Palavras-chave: Fragaria $x$ ananassa, 6-benzilaminopurina, cultura de tecidos, fontes de luz, qualidade da luz, micropropagação.

\section{ABSTRACT}

The objective of this research was to evaluate the effect of different sources of light in strawberry micropropagation, under increasing levels of BAP in culture medium. 'Sabrosa' shoots were inoculated in MS medium supplemented with $30 \mathrm{~g} \mathrm{~L}^{-1}$ sucrose, 100mg $\mathrm{L}^{-1}$ myo-inositol, 7 agar $g L^{-1}$ and $B A P\left(0 ; 0.3\right.$; 0.6; 0.9; e $\left.1.5 m L^{-1}\right)$, $p H$ 5.8. The explants were cultivated at $25+2^{\circ} \mathrm{C}, 16$ hours photoperiod and $20 \mu \mathrm{mol} \mathrm{m} \mathrm{m}^{-2} \mathrm{~s}^{-1}$. The luminosity was supplied by different sources of light (blue-EDEB 3LA1 LED, green-EDET 3LA1 LED, redEDER $3 L A 3$ LED, Growlux fluorescent lamp and white fluorescent lamp). The experimental design was a factorial entirely randomized (5 concentrations of BAP $x 5$ light sources) with six replications. The experiment was repeated in three successive subcultures of 35 days each, being evaluated the shoot number per explant and shoot height. The carotenoids and chlorophyll $a$ and $b$ determinations were carried out after the third subculture, independently of BAP concentration. Shoot number per explant was higher under red and green LEDs. BAP concentrations between 0.82 and $1.22 \mathrm{mg} \mathrm{L}^{-1}$ in culture medium showed higher multiplication rate depending on the light source. Shoot length was highest in culture medium without $B A P$ under all light sources. Shoots cultivated under red LEDs showed higher concentration of photosynthetic pigments, while those under green LEDs and Growlux light bulbs showed the lowest.

Key words: Fragaria $x$ ananassa, 6-benzylaminopurine, tissue culture, light source, light quality, micropropagation.

\section{INTRODUÇÃO}

A cultura do morangueiro (Fragaria $x$ ananassa Duch.) apresenta grande importância econômica e social para milhares de produtores de base familiar dos Estados de São Paulo, Minas Gerais e Rio Grande do Sul (OLIVEIRA\& SCIVITTARO, 2009). Entre

'Embrapa Clima Temperado, 96001-970, Pelotas, RS, Brasil. E-mail: roberto.pedroso@cpact.embrapa.br *Autor para correspondência. "Instituto Federal Sul-riograndense, Pelotas, RS, Brasil. 
as cultivares disponíveis para plantio no Brasil, a 'Sabrosa' é uma das mais recentemente introduzidas. As plantas dessa cultivar são vigorosas, compactas e de hábito de crescimento ereto, sendo o sistema radicular resistente a patógenos; os frutos são muito atrativos, de formato cônico, coloração vermelha brilhante, polpa firme e sabor agradável, com grande quantidade de açúcares (INOTALIS, 2009).

Técnicas de micropropagação têm se mostrado alternativas viáveis para a produção massal de plantas, sendo o morangueiro uma das principais espécies trabalhadas no Brasil e no exterior (OLIVEIRA \& SCIVITTARO, 2009). Entre os reguladores vegetais utilizados na multiplicação in vitro de morangueiro, a 6-benzilaminopurina (BAP) tem sido a de maior uso comercial (BRAHM \& OLIVEIRA, 2004).

A partir dos avanços tecnológicos ocorridos nos anos 90, os diodos emissores de luz (LEDs) passaram a ser utilizados comercialmente nas indústrias automobilísticas, nos centros cirúrgicos, nos projetos arquitetônicos, nas televisões, etc, (STEELE, 2007). Nos últimos anos, seu uso estendeu-se para ambientes de cultivo de plantas micropropagadas (NHUT et al., 2003). No Brasil, ainda não existem estudos com LEDs na multiplicação in vitro de plantas, embora, no exterior, existam relatos de características diferenciadas e dos benefícios dessa fonte de luz (NHUT et al., 2003).

Os LEDs destacam-se das demais fontes de luz por possuírem alta eficiência no processo de geração de luz com baixa produção de calor, pelo longo período de vida, pelo comprimento de onda específico, pela massa e pelo volume pequenos (YEH \& CHUNG, 2009). Contudo, as lâmpadas fluorescentes brancas ainda são as mais difundidas e utilizadas em laboratórios de cultura de tecidos de plantas.

A qualidade da luz, ou seja, o comprimento de onda específico, a densidade de fluxo de fótons e o fotoperíodo influenciam a morfogênese das plantas cultivadas in vitro (LIAN et al., 2002). Estudos sobre a qualidade da luz fornecida por LEDs foram realizados em crisântemo (SILVA \& DEBERG, 1997), bananeira (DUONG et al., 2002) e copo-de-leite (CHANG et al., 2003), buscando-se o refinamento das técnicas de micropropagação e das condições de cultivo utilizadas na obtenção de mudas de melhor qualidade e a valores mais competitivos.

A luz é a fonte de energia para o processo de fotossíntese, o qual regula o desenvolvimento das plantas, sendo os pigmentos, notadamente as clorofilas, importantes na captação da energia luminosa e em sua transformação em energia química (NHUT et al., 2003).
Diante do exposto, o objetivo do trabalho foi avaliar o efeito de fontes de luz na multiplicação in vitro de morangueiro, cultivar 'Sabrosa', com níveis crescentes de BAP no meio de cultura.

\section{MATERIAL E MÉTODOS}

O experimento foi realizado no laboratório de Cultura de Tecidos da Embrapa Clima Temperado, em Pelotas, Rio Grande do Sul (RS), partindo de explantes provenientes da cultura de meristemas de morangueiro. No experimento, utilizaram-se gemas de brotações com três folhas de morangueiro da cultivar 'Sabrosa', medindo $1,5 \pm 0,3 \mathrm{~cm}$ de altura, provenientes de dois subcultivos sucessivos de 35 dias em meio MS (MURASHIGE \& SKOOG, 1962), contendo 0,3 $\mathrm{mg} \mathrm{L}^{-1}$ de BAP, em sala de crescimento com lâmpadas fluorescentes brancas.

As brotações foram introduzidas em frascos de vidro, com capacidade de $250 \mathrm{~mL}$ ( $6,5 \mathrm{~cm}$ de diâmetro e $13 \mathrm{~cm}$ de altura), contendo $40 \mathrm{~mL}$ de meio MS acrescido de $100 \mathrm{mg} \mathrm{L}^{-1}$ de mio-inositol, $30 \mathrm{~g} \mathrm{~L}^{-1}$ de sacarose, $7 \mathrm{~g} \mathrm{~L}^{-1}$ de ágar e cinco concentrações de BAP, estas últimas descritas a seguir, sendo o $\mathrm{pH}$ ajustado para 5,8 após a adição do ágar. A autoclavagem foi realizada à temperatura de $121^{\circ} \mathrm{C}$, a $1,5 \mathrm{~atm}$, por 20 minutos. Nessas condições, foram conduzidos três subcultivos sucessivos de 35 dias, com fontes variáveis de luz, fotoperíodo fixo de 16 horas, temperatura de $25 \pm 2^{\circ} \mathrm{Ce}$ intensidade luminosa de $20 \mu \mathrm{mol} \mathrm{m}^{-2} \mathrm{~s}^{-1}$. Cada subcultivo de explantes de morangueiro constituiu um experimento, no qual foram avaliadas as combinações de concentrações de BAP no meio MS $(0 ; 0,3 ; 0,6 ; 0,9$; e 1,5 $\mathrm{mg} \mathrm{L}^{-1}$ ) com fontes de luz [LED azul-EDEB 3LA1 470nm, LED verde-EDET 3LA1 530nm, LED vermelhoEDER 3LA3 630nm, lâmpada fluorescente Growlux e lâmpada fluorescente branca (tratamento controle)]. Em cada subcultivo, os tratamentos foram dispostos em delineamento inteiramente ao acaso, em um fatorial $5 \times 5$, com seis repetições. As unidades experimentais foram constituídas por frascos contendo cinco explantes. Após cada subcultivo, avaliaram-se o número e o comprimento médio das brotações formadas por explante.

Ao final do terceiro subcultivo, independentemente da concentração de BAP do meio de cultura, coletaram-se amostras de folhas das brotações obtidas sob diferentes fontes de luz (100mg de tecido foliar), para quantificar os teores de carotenoides e de clorofilas $a$ e $b$, em extrato acetônico (80\%). Nessa coleta, amostraram-se todas as folhas produzidas in vitro pelas plantas, independentemente da posição. A quantificação dos pigmentos foi realizada 
por espectrofotometria (clorofila $a=663 \mathrm{~nm}$, clorofila $b=645 \mathrm{~nm}$ e carotenoides $=470 \mathrm{~nm}$ ), segundo LICHTENTHALER(1987).

Os resultados relativos a cada subcultivo foram submetidos à análise de variância, comparandose as médias do fator fonte de luz pelo teste de Duncan e do fator concentração de BAP no meio de cultivo MS, por análise de regressão polinomial. Os dados da variável número de brotações foram transformados em raiz quadrada de $(\mathrm{x}+0,5)$. Para as análises estatísticas, foram adotados $5 \%$ de probabilidade.

\section{RESULTADOS E DISCUSSÃO}

Nos três subcultivos, determinou-se a significância da interação entre os fatores fonte de luz e concentração de BAP no meio de cultivo para as variáveis número e comprimento das brotações de morangueiro.

Apenas nos três subcultivos conduzidos na ausência de BAP não houve efeito da fonte de luz no número de brotações obtidas por explante. Nesses casos, o número de brotações por explante foi pequeno, variando, em média, de 1,0 a 2,4, com redução ao longo dos subcultivos (Figura 1). A redução do número de brotações verificada ao longo dos três subcultivos provavelmente se deve à gradativa redução do nível de BAP existente nos tecidos, haja vista que os explantes foram previamente cultivados em meio MS com $0,3 \mathrm{mg} \mathrm{L}^{-1}$ de BAP (efeito residual). Por outro lado, subcultivos sucessivos de explantes em meio com altas concentrações de BAP causam redução da taxa de multiplicação (OLIVEIRA et al., 2001), conforme observado no tratamento com uso de $1,5 \mathrm{mg} \mathrm{L}^{-1}$ de BAP, no meio de cultura (Figura 1).

Independentemente da concentração de BAP no meio de cultivo, verificou-se maior número de brotações de morangueiro nos três subcultivos sob os LEDs azuis, vermelhos e verdes do que sob as lâmpadas fluorescentes brancas e Growlux (Figura 1). LIAN et al. (2002) já haviam comprovado maior massa fresca e seca de explantes de lírio oriental da cultivar 'Pesaro' (Lilium sp.) cultivados sob LEDs vermelhos e azuis do que sob lâmpadas fluorescentes. Tais resultados sugerem a necessidade de revisão da indicação do uso generalizado de lâmpadas fluorescentes brancas em salas de crescimento de laboratórios de cultura de tecidos. Para TAIZ \& ZEIGER (2004), a menor eficiência de multiplicação e crescimento na presença de lâmpadas fluorescentes brancas decorre do fato destas emitirem diferentes comprimentos de onda entre 350 e $750 \mathrm{~nm}$, e somente entre 400 e 700nm são considerados mais importantes para a fotossíntese. Quanto às lâmpadas fluorescentes Growlux, estas emitem radiação luminosa nos espectros vermelho distante, amarelo e azul, sendo recomendadas principalmente para induzir florescimento (SYLVANIA, 2009). No entanto, na multiplicação e no desenvolvimento in vitro de explantes de morangueiro, essas lâmpadas também foram menos eficientes do que as fontes de luz com base em LEDs, o que demonstra a necessidade de adequação do tipo de fonte de luz para cada fase de desenvolvimento da espécie.

Além da iluminação das salas de crescimento de laboratórios de cultura de tecidos por LEDs proporcionar maior desenvolvimento dos explantes de morangueiro, estas são particularmente vantajosas pela maior vida útil, que pode chegar a 100.000 horas de uso, enquanto que as lâmpadas fluorescentes apresentam vida útil média de 8.000 horas (YEH \& CHUNG, 2009). Em acréscimo, os LEDs são isentos de substâncias tóxicas, como o mercúrio, e apresentam elevada eficiência na conversão de luz (STEELE, 2007). Normalmente, esses fatores compensam o maior custo de instalação de uma sala de crescimento com LEDs do que com lâmpadas fluorescentes (YEH\& CHUNG, 2009).

Nos três subcultivos e para todas as fontes de luz, observou-se resposta quadrática da variável número de brotações de morangueiro ao aumento da concentração de BAP no meio de cultura, tendo sido realizado o teste $F$ para estimar a significância (Figuras 1A, 1B e 1C). O número máximo de brotações por explante verificado no primeiro $(8,4)$, no segundo $(9,0)$ e no terceiro $(6,1)$ subcultivo foi obtido com o uso de concentrações estimadas de 1,$22 ; 0,97 ;$ e $0,82 \mathrm{mg} \mathrm{L}^{-1}$ de BAP, em cultivos sob LEDs vermelho, verde e vermelho, respectivamente. As concentrações de BAP que otimizaram o número de brotações de morangueiro obtidas por explante nos três subcultivos realizados foram próximas àquela recomendada para a espécie, de $1 \mathrm{mg} \mathrm{L}^{-1}$ de BAP (BRAHM \& OLIVEIRA, 2004).

Dessa forma, os LEDs vermelho-EDER 3LA3 e verde-EDET 3LA1 foram as fontes de luz que promoveram maior número de brotações por explante de morangueiro. Até o momento, existem poucas informações sobre os efeitos da iluminação por LEDs na cultura de tecidos de plantas. Contudo, sabe-se que a luz vermelha geralmente emite um espectro próximo ao da absorção máxima das clorofilas e fitocromos, sendo importante para o desenvolvimento do aparato fotossintético e para a acumulação de amido (SAEBO et al., 1995). A luz verde é absorvida por fitocromos e criptocromos, que, possivelmente, influenciam eventos induzidos pela luz (FOLTA, 2004).

Em relação à multiplicação dos explantes de morangueiro cultivados sob lâmpadas fluorescentes 


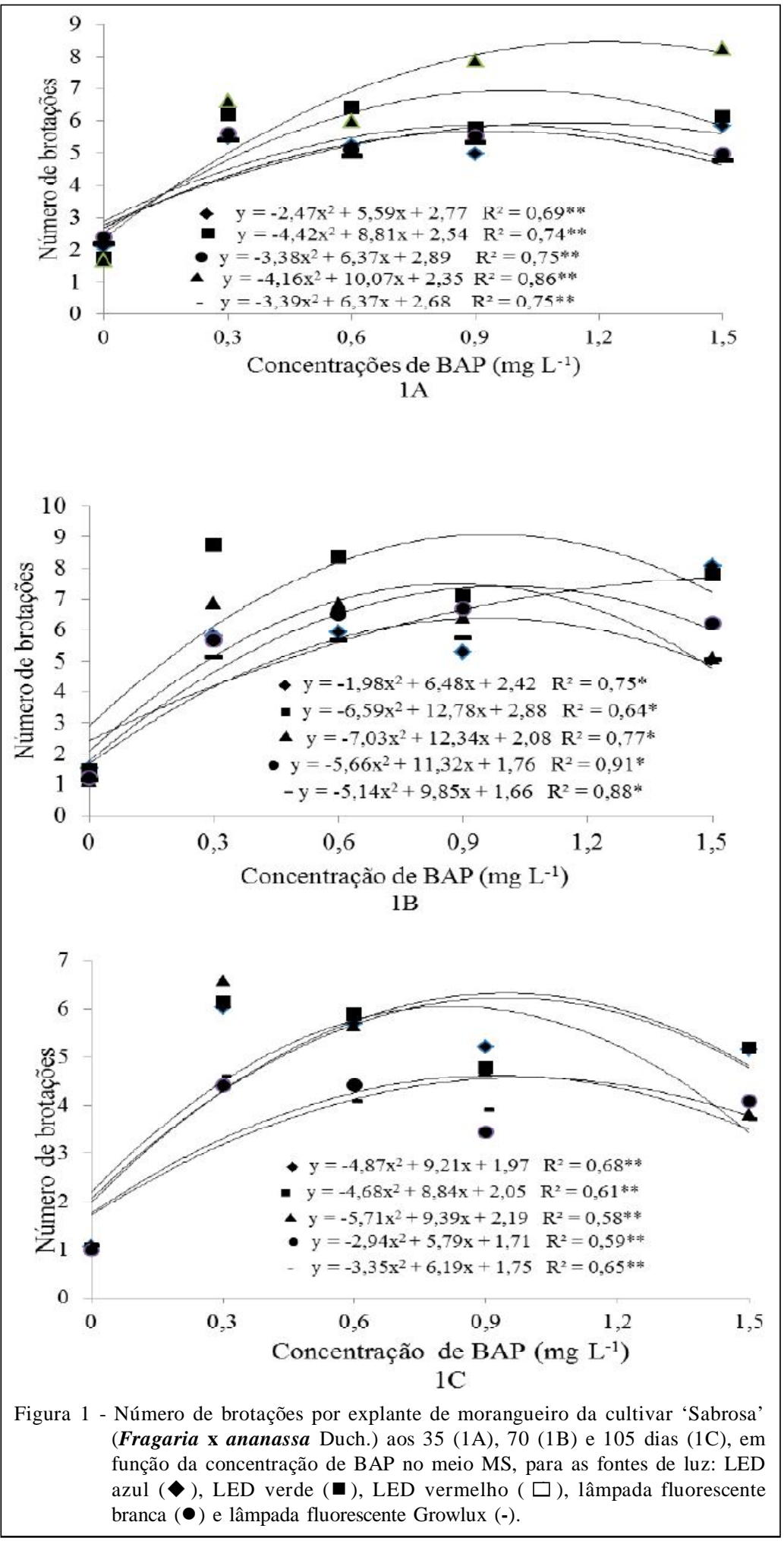

brancas (tratamento controle), o maior número de brotações por explante nos três subcultivos $(5,9 ; 7,4$; e 4,5 brotações por explante) foi obtido nas respectivas concentrações estimadas de BAP: 0,94; 1,00; e 0,98mg
$\mathrm{L}^{-1}$ (Figura 1A, 1B e 1C). As taxas de multiplicação obtidas em cada subcultivo sob luz fluorescente branca, embora tenham sido menores do que as verificadas com os LEDs, encontram-se em níveis semelhantes aos 
descritos na literatura para morangueiro (BRAHM \& OLIVEIRA, 2004).

Quanto ao comprimento das brotações, verificou-se, nos três subcultivos, comportamento quadrático quanto ao aumento da concentração de BAP. As brotações de maior comprimento foram obtidas no meio de cultura sem BAP e cultivadas sob os LEDs verde-EDET 3LA1 (49,7mm), vermelho-EDER 3LA3 $(40,9 \mathrm{~mm})$ e LED azul-EDEB 3LA1 $(48,2 \mathrm{~mm})$, respectivamente, no $1^{\circ}$, no $2^{\circ}$ e e no $3^{\circ}$ subcultivo (Figura 2A, 2B e 2C). De forma geral, independentemente da fonte de luz, o aumento da concentração de BAP no

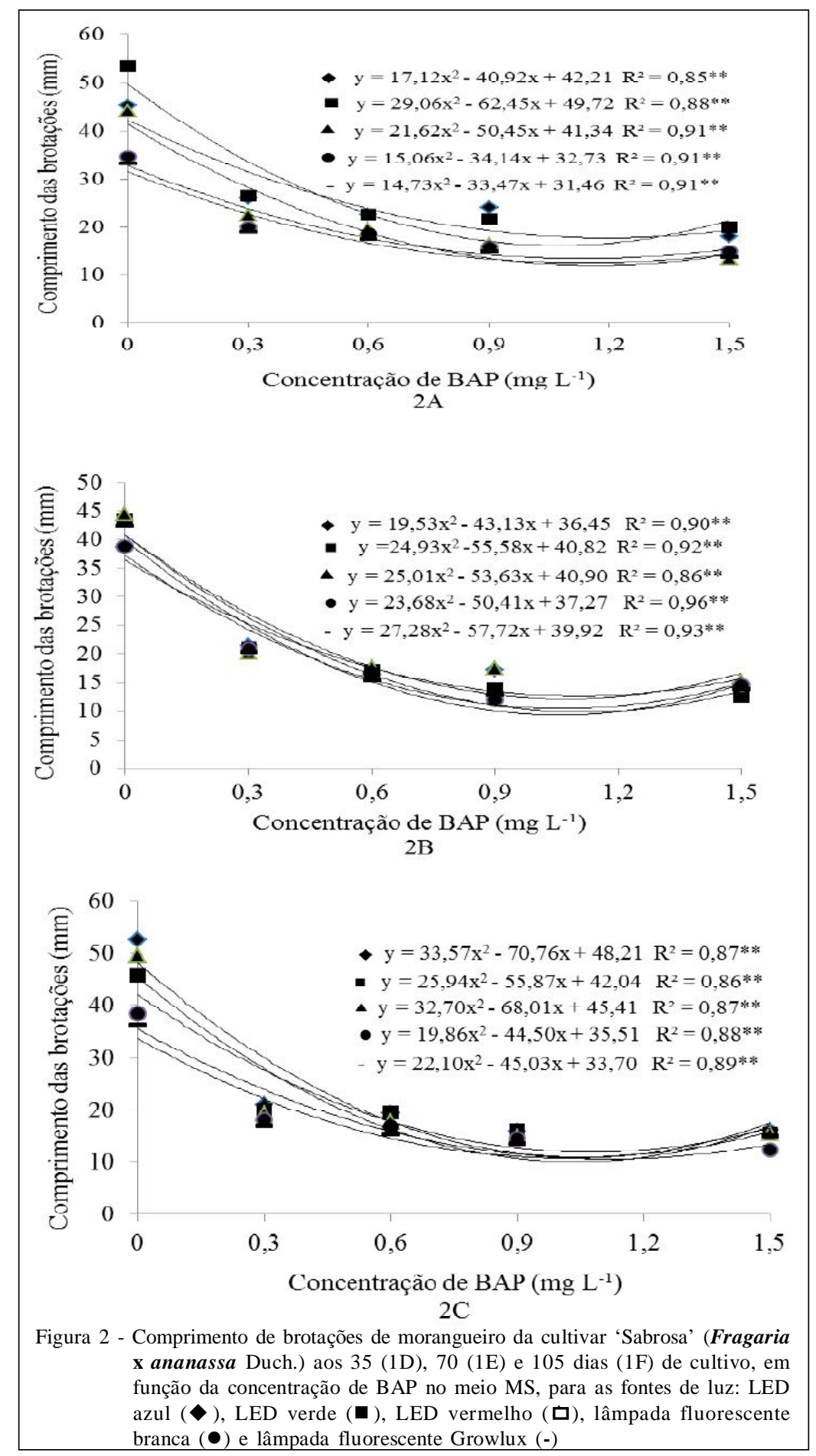

Ciência Rural, v.40, n.9, set, 2010. 
meio de cultura afeta negativamente o crescimento das brotações por induzir a sua proliferação (BRAHM \& OLIVEIRA, 2004). Em função das brotações concorrerem entre si pela absorção de sais e vitaminas presentes no meio de cultivo, estas tendem a ser menores (OLIVEIRA et al., 2001). A superioridade dos LEDs em relação às lâmpadas fluorescentes brancas quanto à obtenção de maior comprimento das brotações havia sido demonstrada em crisântemos (Chrysanthemum sp.) (KIM et al., 2004) e em copo-deleite (Zantedeschia albomaculata) (CHANG et al., 2003). Esses autores obtiveram maior comprimento de brotações sob LEDs vermelhos em crisântemos e sob LEDs vermelhos e azuis em copo-de-leite, demonstrando haver diferença de resposta entre espécies, mas tendência de superioridade dos LEDs vermelhos.

Quanto ao conteúdo de pigmentos fotossintéticos, maiores quantidades de clorofilas $a$ $\left(2,70 \mathrm{mg} \mathrm{g}^{-1}\right)$ e $b\left(0,87 \mathrm{mg} \mathrm{g}^{-1}\right)$ foram determinadas nas brotações de morangueiro cultivadas sob LEDs vermelho-EDER 3LA3. Contrariamente, o cultivo sob LEDs verde-EDET 3LA1 e lâmpadas Growlux proporcionou as menores quantidades desses pigmentos, sendo o efeito decorrente das demais fontes de luz (LEDs azul-EDEB 3LA1 e lâmpadas fluorescentes) intermediário aos demais (Tabela 1).

O conteúdo de carotenoides das brotações cultivadas sob os LEDs vermelho-EDER 3LA3 também foi elevado $\left(1,33 \mathrm{mg} \mathrm{L}^{-1} \mathrm{~g}\right)$, superando aqueles proporcionados nos cultivos realizados sob LED verdeEDET 3LA1 e lâmpada Growlux, com menores quantidades de carotenóides. As quantidades de carotenoides determinadas sob LEDs azul-EDEB 3LA1 e lâmpadas fluorescentes foi intermediário ao das demais fontes de luz (Tabela 1). As clorofilas $a$ e $b$ e os carotenoides (pigmentos acessórios) são pigmentos importantes no processo de fotossíntese, estando diretamente relacionados à multiplicação celular e ao crescimento das plantas. As clorofilas são responsáveis pela absorção e pelo envio de energia luminosa para os centros de reação, enquanto os carotenoides atuam como fotoprotetores (TAIZ \& ZEIGER, 2004). NHUT et al. (2003) também observaram efeito positivo da iluminação proporcionada por LEDs vermelhos, sendo obtida maior quantidade de clorofila em brotações de morangueiro da cultivar 'Akihime' cultivadas sob 70\% de LEDs vermelhos e 30\% de LEDs azuis. Aluz verde é, geralmente, considerada como um tipo de luz de pequena importância para a fotossíntese, principalmente devido ao baixo coeficiente de absorção (KIM et al., 2004), fato que pode explicar o menor conteúdo de carotenoides sob LEDs verdes.

\section{CONCLUSÃO}

Os LEDs apresentam elevado potencial para serem utilizados como fonte de luz na micropropagação de morangueiro, sendo os LEDs vermelho-EDER 3LA3 e verde-EDET 3LA1 os que promovem maior número de brotações por explante. Os LEDs vermelho-EDER 3LA3 também proporcionam maior quantidade de clorofilas $a$ e $b$ nas brotações cultivadas in vitro.

Maior número de brotações por explante é obtido com o uso de concentrações de 1,22; 0,97; e $0,82 \mathrm{mg} \mathrm{L}^{-1}$ de BAP em cultivos sob LEDs vermelho, verde e vermelho, respectivamente.

\section{AGRADECIMENTOS}

Ao Conselho Nacional de Pesquisa e Desenvolvimento Tecnológico (CNPq) e à Fundação de Amparo à Pesquisa do Estado do Rio Grande do Sul (FAPERGS), pelo financiamento do projeto e pela concessão de bolsas.

Tabela 1 - Conteúdo ( $\left.\mathrm{mg} \mathrm{g}^{-1}\right)$ de carotenoides e de clorofilas $a$ e $b$ em brotações de morangueiro da cultivar 'Sabrosa' (Fragaria $\mathbf{x}$ ananassa Duch.), em função da fonte de luz. Avaliação realizada ao final do terceiro subcultivo.

\begin{tabular}{llcl}
\hline Fonte de luz & Carotenoides & Clorofila $a$ & Clorofila $b$ \\
\hline & & & \\
LED azul-EDEB 3LA1 & $1,20 \mathrm{abc}^{*}$ & $2,36 \mathrm{~b}$ & $0,70 \mathrm{c}$ \\
LED verde-EDET 3LA1 & $0,99 \mathrm{c}$ & $1,82 \mathrm{c}$ & $0,58 \mathrm{~d}$ \\
LED vermelho-EDER 3LA3 & $1,33 \mathrm{a}$ & $2,70 \mathrm{a}$ & $0,87 \mathrm{a}$ \\
Lâmpada fluorescente branca & $1,32 \mathrm{ab}$ & $2,39 \mathrm{~b}$ & $0,80 \mathrm{~b}$ \\
Lâmpada fluorescente Growlux & $1,03 \mathrm{bc}$ & $1,89 \mathrm{c}$ & $0,63 \mathrm{c}$ \\
CV $(\%)$ & 4,7 & 3,1 & 2,1 \\
\hline
\end{tabular}

* Médias não seguidas de mesma letra nas colunas diferem significativamente entre si pelo teste de Duncan, a 5\% de probabilidade. 


\section{REFERÊNCIAS}

BRAHM, R.U.; OLIVEIRA, R.P. Pontencial de multiplicação in vitro de cultivares de morangueiro. Revista Brasileira de Fruticultura, Jaboticabal, v.26, n.3, p.507-510, 2004. Disponível em: 〈http://www.scielo.br/pdf/rbf/v27n2/a09v27n2.pdf〉. Acesso em: 31 maio, 2010. doi: 10.1590/S0100-29452005000200009.

CHANG, H.S. et al. Micropropagation of calla lilly (Zantedeschia albomaculata) via in vitro shoot tip proliferation. In Vitro Cellular and Developmental Biology, New York, v.39, p.129-134, 2003. Disponível em: <http://www.jstor.org/ pss/4293581>. Acesso em: 31 maio, 2010. doi: 10.1079/ 1 VP2002362.

DUONG, T.N. et al. Growth of banana plantlets cultured in vitro under red and blue light-emitting diode (LED) irradiation source. Acta Horticulturae, The Hague, n.575, p.117-124, 2002. Disponível em: <http://www.actahort.org/members/ showpdf?session=19925>. Acesso em: 31 maio, 2010.

FOLTA, K.M. Green light stimulates early stem elongation, antagonizing light-mediated growth inhibition. Plant Physiology, Bethesda, v.135, p.1407-1416, 2004. Disponível em: <http://www.ncbi.nlm.nih.gov/pmc/articles/PMC519058/ pdf/pp1351407.pdf>. Acesso em: 31 maio, 2010. doi: 10.1104/ pp.104.038893.

KIM, S.J. et al. Effects of LEDs on net photosynthetic rate, growth and leaf stomata of chrysanthemum plantlets in vitro. Scientia Horticulturae, Amsterdam, v.110, p.143-151, 2004. Disponível em: <http://www.sciencedirect.com/ science?_ob=ArticleURL\&_udi=B6TC3-4B4XTMS$1 \& \_$user $=5889052 \& \_$rdoc $=1$ \&_fmt $=$ \&_orig $=$ search $\& \_s o r t=$ d\&_docanchor $=\& v i e w=c \& \_s e a r c h S t r I d=1127137041$ \&_rerunOrigin $=$ google\&_acct $=$ C0000 $12878 \&$ \& version $=1 \&$ \&urlVersion $=$ 0\&_userid=5889052\&md5=51867f0cec1666d20fd7a 7ff0a9338b9>. Acesso em: 31 maio, 2010. doi: 10.1016/j.scienta.2003.10.003.

INOTALIS - Innovación en variedades vegetales. Candonga. Acesso em: 20 jul. 2009. Online. Disponível em: http://inotalis.com/ index.php?option=com_content\&task $=$ view\&id $=26 \& I$ temid $=57$.

LIAN, M.L. et al. Effects of light emitting diodes (LEDs) on the in vitro induction and growth of bulblets of Lilium oriental hybrid 'Pesaro'. Scientia Horticulturae, Amsterdam, v.94, p.365370, 2002. Disponível em: <http://www.sciencedirect.com/ science?_ob=ArticleURL\&_udi=B 6TC3-44Y0WBJ$1 \&$ \&user $=5889052 \&$ \&doc $=1 \&$ \& fmt $=\&$ \&orig $=$ search $\&$ _sort $=$ d\&_docanchor $=\&$ view $=c \&$ c searchStrId $=11$ $27147813 \&$ \&erunOrigin $=$ google \&_a c ct $=$ C 000 $012878 \&$ \& version $=1 \&$ \& urlVersion $=0 \&$ \&_userid $=58$ $89052 \& \mathrm{md} 5=\mathrm{b} 316084 \mathrm{c} 64 \mathrm{e} 510 \mathrm{~d} 9 \mathrm{ab} 3 \mathrm{~d} 7 \mathrm{cc} 5098 \mathrm{a} 2 \mathrm{f} 25>$. Acesso em: 31 maio, 2010. doi: 10.1016/S0304-4238(01)00385-5.

LICHTENTHALER, H.K. Chlorophylls and carotenoids, the pigments of photosynthetic biomenbranes. In: DOUCE, R.; PACKER, L. (Ed.). Methods in enzymology. Washington: Academic, 1987. Cap.1, p.350-382.
MURASHIGE, T.; SKOOG, F. A revised medium for rapid growth and bioassays with tobacco tissue cultures. Physiologia Plantarum, Copenhagen, v.15, p.473-497, 1962.

NHUT, D.T. et al. Responses of strawberry plantlets cultured in vitro under superbright red and blue light-emitting diodes (LEDs). Plant Cell, Tissue and Organ Culture, The Hague, v.73, p.43-52, 2003. Disponível em: <http://www.springerlink.com/ content/q84t218176g53112/>. Acesso em: 31 maio, 2010. doi: 10.1023/A: 1022638508007 .

OLIVEIRA, R.P.; SCIVITTARO, W.B. Produção de frutos de morango em função de diferentes períodos de vernalização das mudas. Horticultura Brasileira, Brasília, v.27, n.1, p.9195, 2009. Disponível em: <http://www.scielo.br/ scielo.php ? script=sci_arttext\&pid=S 0102 05362009000100018>. Acesso em: 31 maio, 2010. doi: 10.1590/S0102-05362009000100018.

OLIVEIRA, R.P. et al. Concentração de BAP e a eficiência de micropropagação de bananeira tetraplóide (grupo AAAB). Scientia Agrícola, Piracicaba, v.58, p.73-78, 2001. Disponível em: 〈http://www.scielo.br/pdf/sa/v58n1/a13v58n1.pdf〉. Acesso em: 31 maio, 2010. doi: 10.1590/S0103-90162001000100013.

SAEBO, A. et al. Light quality affects photosynthesis and leaf anatomy of birch plantlets in vitro. Plant Cell, Tissue and Organ Culture, The Hague, v.41, n.2, p.177-185, 1995 Disponível em: <http://www.springerlink.com/content/ g70081310168743j/fulltext.pdf >. Acesso em: 31 maio, 2010.

SILVA, M.H.M.; DEBERGH, P.C. The effect of light quality on the morphogenesis of in vitro cultures of Azorina vidalli (Wats.) Feer. Plant Cell, Tissue and Organ Culture, The Hague, v.51, p.187-193, 1997. Disponível em: <http:// www.springerlink.com/content/w728324k5284236g/ fulltext.pdf $>$. Acesso em: 31 maio, 2010. doi: 10.1023/ A: 1005988621036.

STEELE, R.V. The story of a new light source. Nature, London, v.1, p.25-26, 2007. Disponível em: <http:// www.nature.com/nphoton/journal/v $1 / \mathrm{n} 1 / \mathrm{abs} /$ nphoton.2006.44.html>. Acesso em: 31 maio, 2010. doi:10.1038/nphoton.2006.44.

SYLVANIA. Growlux fluorescent bulb lamps. Acessado em: 06 dez. 2009. Online. Disponível em: http://www.sylvania.com.

TAIZ, L.; ZEIGER, E. Fisiologia vegetal. Porto Alegre: Artmed, 2004. 719p

YEH, N.; CHUNG, J.P. High-brightness LEDs - Energy efficient lighting sources and their potential in door plant cultivation. Renewable and Sustainable Energy Reviews, Taiwan, p.16, 2009. Disponível em: <http://www.sciencedirect.com/ science?_ob=ArticleURL\&_udi=B 6VMY-4VP4WYY$6 \&$ _user $=5889052 \&$ rdoc $=1 \&$ \& $\mathrm{mt}=\&$ \&orig $=$ search $\&$ sort $=$ d\&_docanchor $=\&$ view $=c \&$ \&_searchStrId $=112717$ 2459 \&_rerunOrigin $=$ google\&_acct $=$ C 0000128 $78 \&$ \& version $=1 \&$ \&ur 1 Version $=0 \&$ \& userid $=588$ $9052 \& m d 5=e 08$ f8ab5b4d6e $4 a 9 e 8 a 8$ e730db3a3d89>. Acesso em: 31 maio, 2010. doi: 10.1016/j.rser.2009.01.027. 